\title{
ESTIMATION OF THE AGENT BEHAVIORS BY USING THE TAYLOR SERIES APPROXIMATION
}

\author{
Sevcan Emek ${ }^{*}$, Şebnem Bora ${ }^{2}$ \\ ${ }^{1}$ Manisa Celal Bayar University, Engineering Faculty, Department of Computer Engineering, Manisa, Turkey \\ ${ }^{2}$ Ege University, Engineering Faculty, Department of Computer Engineering, Izmir, Turkey
}

\begin{tabular}{ll}
\hline Keywords & Abstract \\
\hline $\begin{array}{l}\text { Agent, } \\
\text { Agent-based model, }\end{array}$ & In the agent-based modeling approach, agents play an important role in \\
Taylor Series. & determining the behavior of the system. The agents are autonomous components \\
of the agent-based model of a real system. An agent is defined as having a set of \\
features and rules governing behavior and decision-making. In this study, a \\
numerical solution is presented for determining some rules of behaviors of agents. \\
Behavioral functions that will guide the actions of the agents in the model are \\
handled with the Taylor series approach. The Taylor series can estimate a function \\
value at the initial agent in terms of the function value and its derivatives at \\
another agent. An agent-based cross-sectional model is examined with some \\
experimental results by using Taylor series expansion. Compared to the results of \\
the study which is presented with the agent-based modeling approach, the Taylor \\
Series obtains successful solutions based on distance points of the agents. This \\
study presents a hybrid model perspective by proposing a numerical method \\
approach to determining agent behaviors.
\end{tabular}

\section{TAYLOR SERİSİ İLE ETMEN DAVRANIŞLARININ TAHMİNLENMESİ}

\begin{tabular}{l} 
Anahtar Kelimeler \\
\hline Etmen, \\
Etmen tabanll modelleme, \\
Taylor Serisi.
\end{tabular}

Taylor Serisi.

\begin{abstract}
Öz
Etmen tabanlı modelleme yaklaşımında, modellenen sistemin davranışının belirlenmesinde etmenler önemli rol oynamaktadır. Etmenler gerçek bir sistem modelinin otonom bileşenleridir. Bir etmen, davranışlarını ve karar verme yeteneğini yöneten bir dizi özellik ve kurala sahip olarak tanımlanmaktadır. $\mathrm{Bu}$ çalışmada, etmenlerin bazı davranış kurallarının belirlenmesinde nümerik bir çözüm sunulmaktadır. Model içinde etmenlerin eylemlerini gerçekleştirmesine yön verecek davranış fonksiyonları Taylor serisi yaklaşımı ile ele alınmaktadır. Taylor serisi, başlangıç etmenindeki bir fonksiyon değerini, fonksiyon değeri ve başka bir ajandaki türevleri açısından tahmin edebilmektedir. Etmen tabanlı kesitsel bir model, Taylor serisi açılımı kullanılarak bazı deneysel sonuçlarla incelenmektedir. Etmen tabanlı modelleme yaklaşımı ile sunulan çalışmanın sonuçları karşılaştırıldığında Taylor Serisi, etmenlerin uzaklık noktalarına göre başarılı çözümler elde etmektedir. Bu çalışma, etmen davranışlarına nümerik bir metot yaklaşımı önermesi ile hibrid bir model perspektifi sunmaktadır.
\end{abstract}

Alıntı / Cite

Emek, S., Bora, Ş., (2020). Estimation of the Agent Behaviors by Using the Taylor Series Approximation, Journal of Engineering Sciences and Design, 8(5), 35-44.

\begin{tabular}{l|l|l}
\hline Yazar Kimliği / Author ID (ORCID Number) & \multicolumn{3}{|l}{ Makale Süreci / Article Process } \\
\hline Author1 S. Emek, 0000-0003-2207-8418 & Başvuru Tarihi / Submission Date & 20.11 .2020 \\
Author2 Ş. Bora, 0000-0003-0111-4635 & Revizyon Tarihi / Revision Date & 22.12 .2020 \\
& Kabul Tarihi / Accepted Date & 22.12 .2020 \\
& Yayım Tarihi / Published Date & 29.12 .2020 \\
\hline
\end{tabular}

\footnotetext{
* ilgili yazar / Corresponding author: sevcan.emek@cbu.edu.tr, +90-236-201-2117
} 


\section{Introduction}

Modeling of the living systems' behaviors helps in solving the numerous engineering problems. The model of a system is an important computational approach that simplifies understanding of the system which involves a number of interacting agents. The term agent refers to an entity of the system. Agents act and interact with each other and/or their environment to carry out their tasks. The behavior of the system occurs as a result of the interaction among the agents. The agents have a decision making mechanism through which they can assess their status within the system. Their decision making mechanism is defined by the basis of a set of rules (Bonabeau, 2002). The modeling method, in which the entity/individual/element of the system are defined as agent, takes place in the literature as an agent-based modeling approach. Agent-based modeling (ABM) has a potential natural description in understanding and managing of the real-world system (Emek, 2018). ABM is a suitable modeling approach for large scale problems. Compared to variable-based approaches using structural equations or system-based approaches using differential equations, it naturally addresses multiple analysis scales that are not easy to model, macro or social structures arising from individual actions, and various types of adaptation and learning (Emek, 2018).

It can be inefficient to use a single method in system models where some assumptions and abstractions are required. Each technique can have the potential to be superior to each other based on different scenarios or problem solutions. In this study, an agent-based model and Taylor Series method which provides a numerical approach to this model are examined with some experimental results. The Taylor Series enables realistic solution of the complex problems. The agent-based models can sometimes make abstractions and assumptions to demonstrate systems' behaviors. However, numerical methods provide solutions without the need for assumptions. When the literature studies are examined, agent-based modeling approach is applied in many fields with artificial intelligence techniques (Bonabeau, 2002; Emek, 2018). Taylor Series can exhibit effective results when used with different modeling techniques. The study of Mangai vd. (2014) presents the Taylor Series algorithm to predict the linear part by using the Artificial Neural Network. Taylor Series is one of the frequently used numerical methods in computer science and computational techniques to estimate function parameters.

This study provides an estimation of the cross-sectional function, which is one of the local behavioral properties of the agents (Bora vd., 2017), by using Taylor series expansion. In this study, the Taylor Series estimates the function value of the agents based on their distance point (step size) to each other. Compared to the results of the study which is presented with the ABM approach, the Taylor series obtains successful solutions based on distance points of the agents.

This paper is organized into 4 parts. Section 2 offers a brief account of ABM. Section 3 presents the modeling of the agent behaviors including some experimental studies by applying the Taylor series to ABM. And the last section concludes with a brief summary including some recommendations for future research directions.

\section{Agent-based Modeling}

Agent-based modeling ( $\mathrm{ABM}$ ) has a different ideology from other applicable modeling techniques with its theoretical foundations, conceptual approach and philosophy, it is an artificial intelligence technique. Its most common use is to model social and organizational behaviors, social interaction and collaboration, individual decision making processes (Bonabeau, 2002; Emek, 2018; Macal and North, 2009). Although ABM is technically easy to apply, it can deepen conceptually and produce different results. The emergence as a result of the interaction of individuals within the system is one of the most important features of ABM. ABM offers a canonical approach that tries to model emerging events by modeling the behaviors of the agents and their interactions (Di Marzo Serugendo vd., 2005; Macal and North, 2010). A bottom-up approach is observed throughout the simulation period to ensure the observation of emerging events. The behaviors of individuals in the real world are non-linear. It can reveal facts such as memory, hysteresis, dependence on a track or path, non-markov behavior or temporal correlations, including individual behavior, learning and adaptation (Bonabeau, 2002; Emek, 2018). For this reason, ABM can characterize such situations with a threshold value or condition if-else structures. ABM includes a set of agents representing real actors in a real system. Agents interact with other agents or system components and have an environment in which they try to perform their individual actions (Bora vd., 2017; Macal and North, 2010).

$\mathrm{ABM}$ has the potential to produce portable, extensible and transferable software with better integrated development environments and better application examples. In order to use a powerful technique such as ABM, it is first necessary to define the components of the real system to be represented, the relationships and interactions between the components. It is important to decide whether or not to use ABM according to the scenario of the system (Di Marzo Serugendo vd., 2005). 


\section{Modeling the Agent Behaviors}

The attributes and actions of the agents, like every software object, must be defined in the system modeling. Attributes of the agents are defined by primitive values and characterize the internal states of the agents. Actions of agents are the most important part of ABM. The agents, their attributes, system states and environment are important components that make up a system model. The behavior of the system is the result of the actions of the agents within the system and their interactions with each other. The actions of the agents allow very high definitions of behaviors for the agent. It can be considered similar to methods in a traditional object-oriented model, but it is specific to agents. The action is not equivalent to an instruction, a method, or a query, but it can have aspects to all of them. Actually, it briefly represents what the modeler wants agents to do. The actions are linked to a range of resources and goals. The result of the previous action starts the workflow of the next action, thereby giving the action "flow" from the exit of an action to the next action (Emek, 2018).

One of the basic principles of ABM is that only local information is available for an agent. There is no central authority that pushes globally available information to all agents or controls their behavior to optimize system performance.

Agents have an environment where they can interact and communicate with other agents. The agents can move around randomly or according to some rules in their environment. The rules and the actions play an important role in the behavior of the agents. The rules that determine the behavior of the agents can be assigned depending on some computational methods, functions or algorithms.

\subsection{Computer-based Methods}

In this study, a sample cross-sectional model consisting of the agents that are the study of Bora vd. (2017) will be examined. In this cross-sectional model, the agents represent cross-cut segments at equal intervals in the form of a narrowing straight pipe shown as Figure 1.

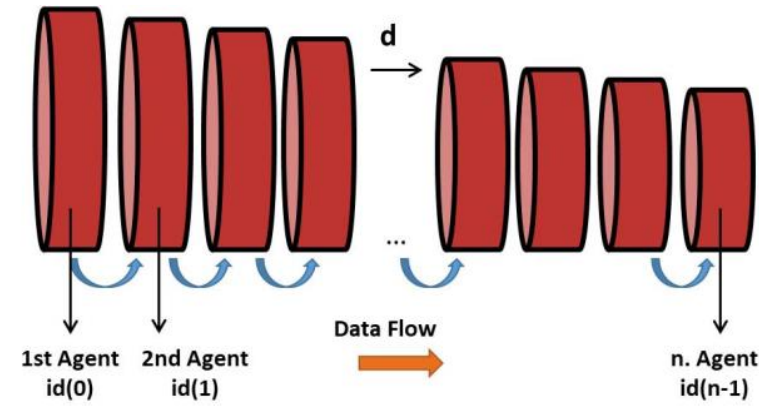

Figure 1. The sample agent-based cross-sectional model (Bora vd., 2017)

The attribute of each agent is defined by its own identity information (id). The incoming information is transmitted from the first agent to the last agent. The agents are of the same type and have the same length.

The set of all agents is denoted by $A$ class. The attributes of agents are defined by each $A_{i_{n}}$ in terms of $n$ for all $n \in$ $N$. The identity of the agents is defined by $i$ (Bora vd., 2017).

$$
A_{i}=\left\{A_{i_{0}}, A_{i_{1}}, \ldots, A_{i_{n}}\right\}
$$

The state of agents which is defined $A_{j}$ for each time-dependent $A_{i}$ is defined as follows (Bora vd., 2017).

$$
A_{j i}^{t}=\left\{A_{j i_{0}}^{t}, A_{j i_{1}}^{t}, A_{j i_{2}}^{t}, \ldots, A_{j i_{n}}^{t}\right\}
$$

The characteristic properties of the agents include location on the coordinate plane, angle and radius information. The radius is an important feature in the expansion or contraction of the agents and can vary over time. Based on the characteristic parameters, the local behaviors of agents emerge from the information received from the environment and the interactions with each other. 
The behavior of the cross-sectional model shown in Figure 2 results from the local behaviors of the agents and their interactions with each other.

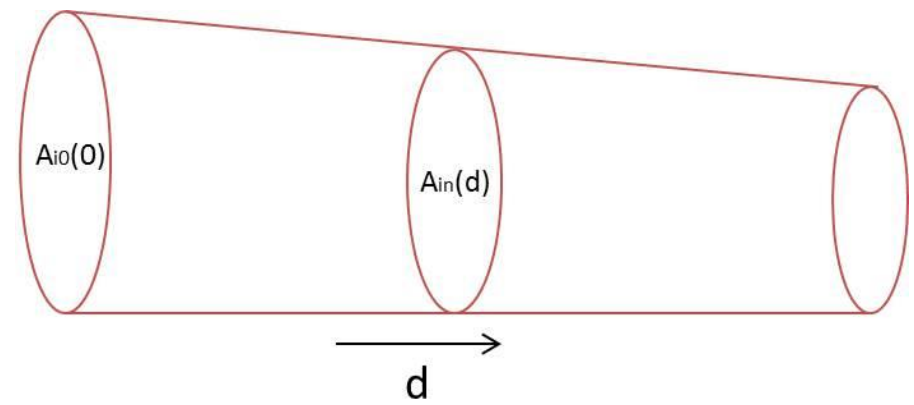

Figure 2. The cross-sectional model formed by the agents (Emek, 2018; Li, 2004)

For the continuity of the data flow, hydrodynamic equations belonging to this cross-sectional model should be used. The diameter decreases as the distance (d) from the starting point (origin) increases by moving from the first to the last agent, as shown in Figure 2. The cross-sectional area $(A)$ of each agent is calculated by equation (3) in accord with the exponential function of the distance (Emek, 2018; Bora vd., 2017; Li, 2004).

$$
A_{i}(d)=A_{i 0}(d) e^{-k_{0} d}
$$

- $d$ : longitudinal axial distance along the model

- $r$ : the radius of the agent $(\mathrm{cm})$,

- $k_{0}$ : tapering factor

- $A_{i 0}(d)$ : the cross-sectional area of the initial agent $\left(\mathrm{cm}^{2}\right)$

- $A_{i}(d)$ : the cross-sectional area of the agent at distance $\mathrm{d}$ along model $\left(\mathrm{cm}^{2}\right)$.

The tapering factor is a parameter used for the geometrical structure of a gradually narrowing tubular biological structure. $A_{i 0}$ is the cross-sectional area of the initial agent calculated by equation (4):

$$
A_{i 0}(d)=P I x r_{i 0}^{2} \quad \mathrm{~d}=0
$$

The radius of the other agents ( $\mathrm{n}^{\text {th }}$ agent) is calculated by equations (5):

$$
r_{\text {in }}^{t}=\sqrt{\frac{A_{i 0}(0) x e^{\frac{-k_{0} \times n \times \text { agent_length }}{r_{i 0}}}}{P I}}
$$

The agent length is calculated by equation (6) as the ratio of the length of the cross-sectional model (model_length) to the number of agents (agent_count), both of which are entered by the programmer:

$$
\text { agent_length }=\frac{\text { model_length }}{\text { agent_count }}
$$

The agents can update their current situation and adapt to the new situation according to the data flow. For example, a message received by the agent may be in the form of its expansion or contraction. For this reason, the agent must adjust its parameters of its behavior such as volume, radius and area. These parameters are set by the if-else structure in the algorithm.

\subsection{Taylor Series}

Taylor series provides an approximate solution to predict a function value. The prediction of the function value at one point and its derivatives at another point is provided by Taylor Series expansion which is built it term by term (Chapra and Canale, 2015; Mangai vd., 2014). The first term in the Taylor Series is

$$
f\left(x_{i+1}\right) \cong f\left(x_{i}\right)
$$


The additional terms of the Taylor Series are the derivatives of the first term to provide a better estimate. The additional first-order term is

$$
f\left(x_{i+1}\right) \cong f\left(x_{i}\right)+f^{\prime}\left(x_{i}\right)\left(x_{i+1}-x_{i}\right)
$$

The function $f$ changes at the interval containing $x_{i+1}$ and $x_{i}$. The step size (h) is

$$
h=x_{i+1}-x_{i}
$$

The expanded version of the Taylor Series is

$$
f\left(x_{i+1}\right) \cong f\left(x_{i}\right)+f^{\prime}\left(x_{i}\right) h+\frac{f^{\prime \prime}\left(x_{i}\right)}{2 !} h^{2}+\frac{f^{\prime \prime \prime}\left(x_{i}\right)}{3 !} h^{3}+\cdots+\frac{f^{n}\left(x_{i}\right)}{n !} h^{n}+R_{n}
$$

$R_{n}$ is the reminder of the Taylor Series which is the error term for the approximation of the function.

\subsection{Applying Taylor Series to Agents}

In this study, the function value that defines the rules of the agents' behaviors is estimated by using the Taylor Series. It is important for an agent in a system to plan its next behavior or/and to estimate the behaviors of the other agents. In equation (3), the cross-sectional areas of the agents at distance $\mathrm{d}$ are calculated by referring to the initial agent $\left(\mathrm{A}_{0}\right)$. The cross-sectional areas of the agents are shown in the Figure 3.

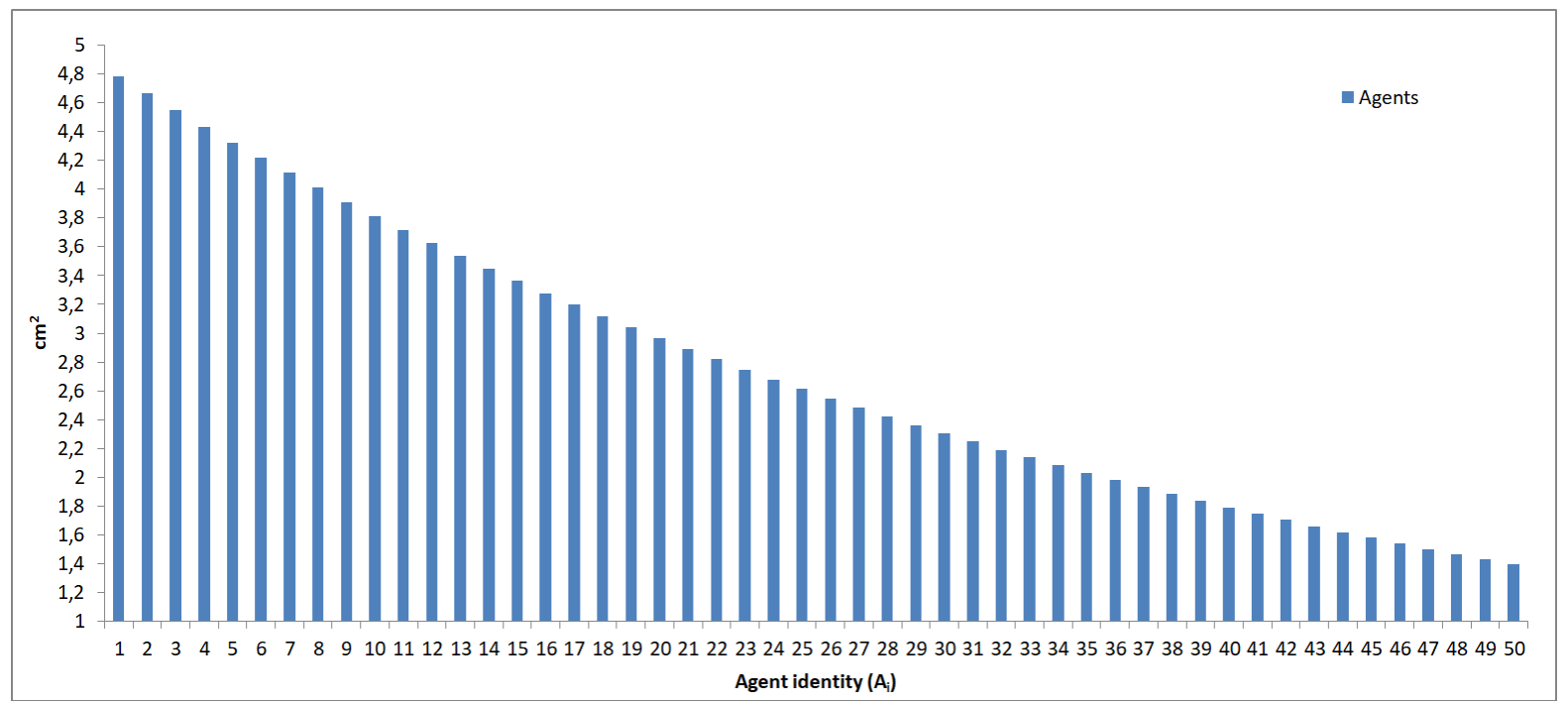

Figure 3. The cross-sectional areas of the agents

In the Figure 4 , the function $f$ value of the agents between initial agent $\left(A_{0}\right)$ and $i^{\text {th }}$ agent $\left(A_{i}\right)$ is calculated by using the Taylor Series. The Taylor Series has been expanded to the third-order term. 


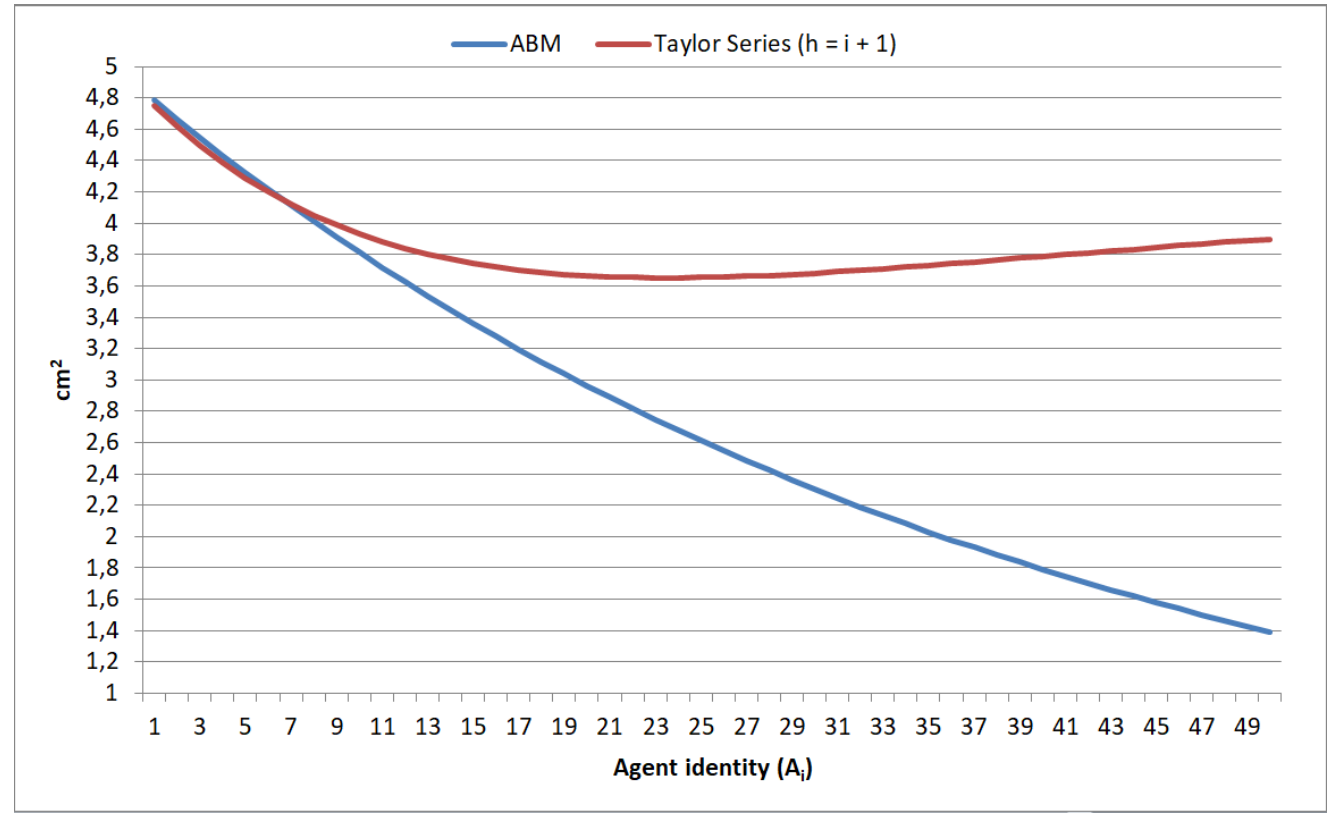

Figure 4. The function value of the agents for $h=i+1$ agent_count

In Figure 4, the Taylor Series has predicted the cross-sectional area function values of the agents by referring to the initial agent $\left(x_{i}=A_{0}\right)$. When calculating the function value of the next agent by applying the Taylor series, the step size (h) is the agent count (equation (6)) between the initial agent $\left(\mathrm{x}_{\mathrm{i}}=\mathrm{A}_{0}\right)$ and the next agent $\left(\mathrm{x}_{\mathrm{i}+1}=\mathrm{A}_{\mathrm{i}}\right)$. Figure 4 shows that Taylor Series has predicted the expected value until the $7^{\text {th }}$ agent. As step size (h) increases, that is, the agents move away from the initial agent, it becomes difficult to estimate the function values of the next agents, and the Taylor Series has exhibited the true relative error in the function values of other agents.

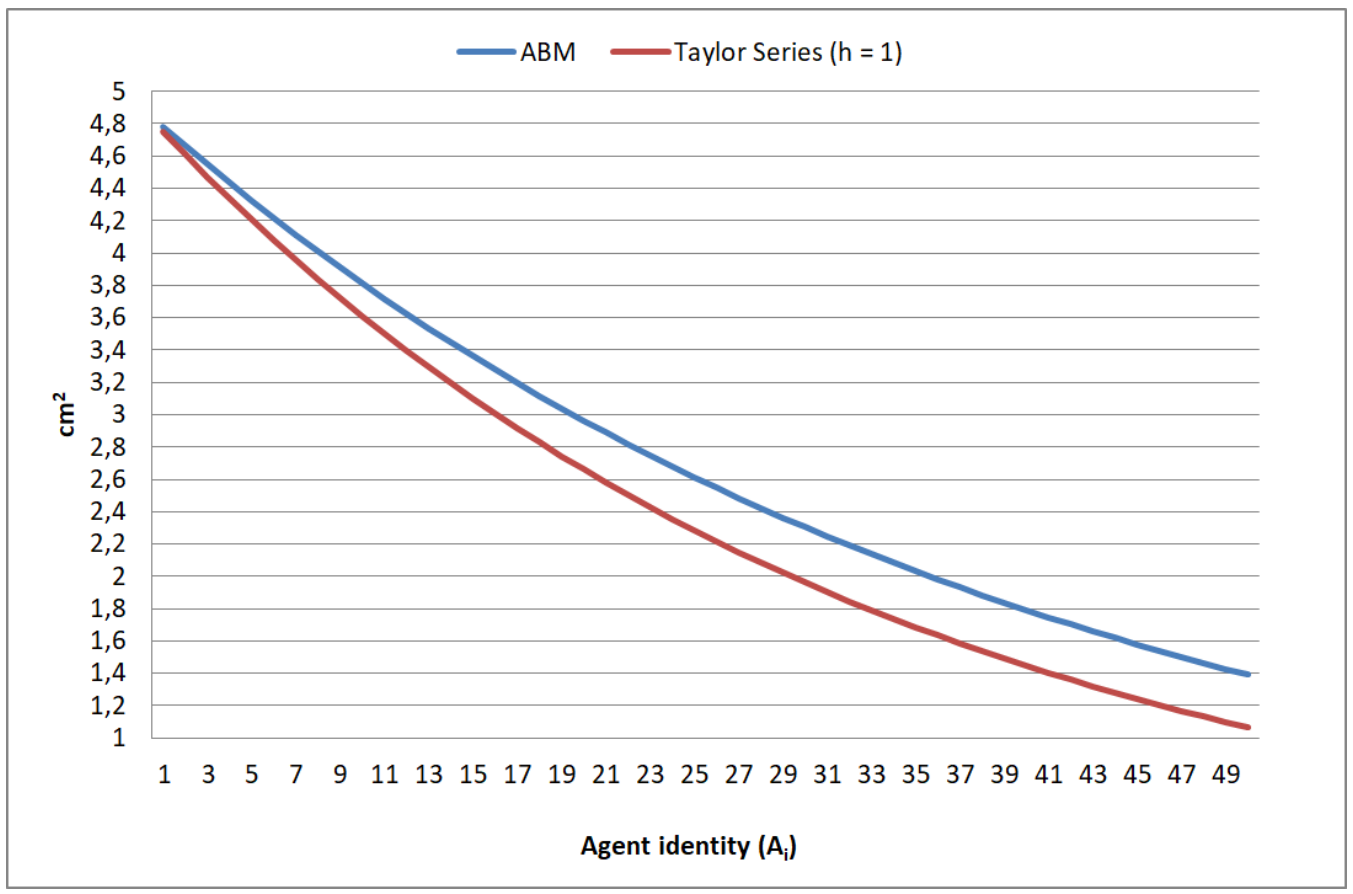

Figure 5. The function value of the agents for $\mathrm{h}=1$ agent_count

In Figure 5, the Taylor Series has predicted the function value of the next agent $\left(A_{i+1}\right)$. When calculating the function value of the next agent by applying the Taylor series, the step size (h) is determined as 1 which is the agent count (equation (6)) between the current agent $\left(x_{i}=A_{i}\right)$ and the next agent $\left(x_{i+1}=A_{i}\right)$. Unlike Figure 4, Figure 5 shows that the Taylor Series has exhibited a curve close to the expected value. 


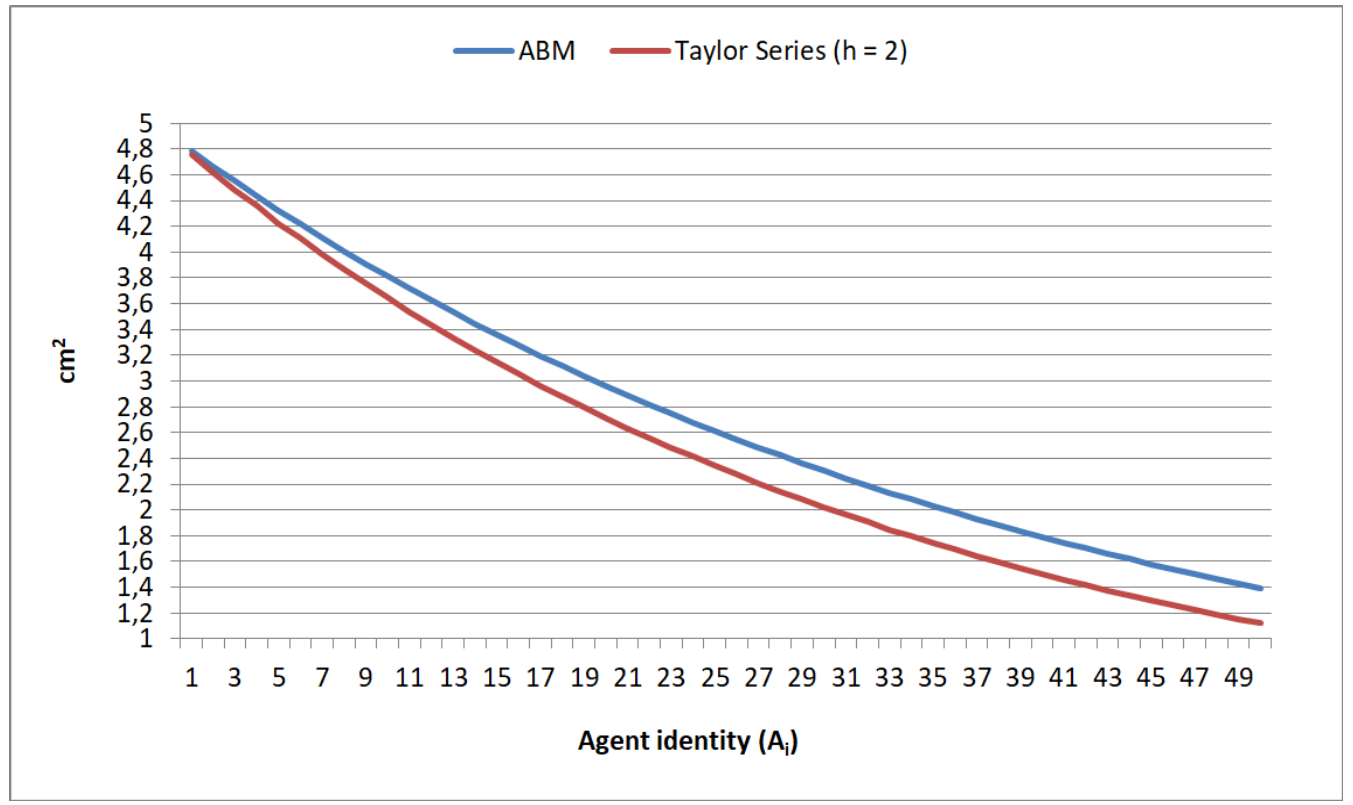

Figure 6. The function value of the agents for $\mathrm{h}=2$ agent_count.

In Figure 6, the Taylor Series has predicted the function value of the agents at a distance of 2 step sizes from each other. When calculating the function value of the next agent by applying the Taylor series, the step size (h) is determined as 2 which is the agent count (equation (6)) between the current agent $\left(\mathrm{x}_{\mathrm{i}}=\mathrm{A}_{\mathrm{i}}\right)$ and the next agent $\left(\mathrm{x}_{\mathrm{i}+1}=\mathrm{A}_{\mathrm{i}+2}\right)$.

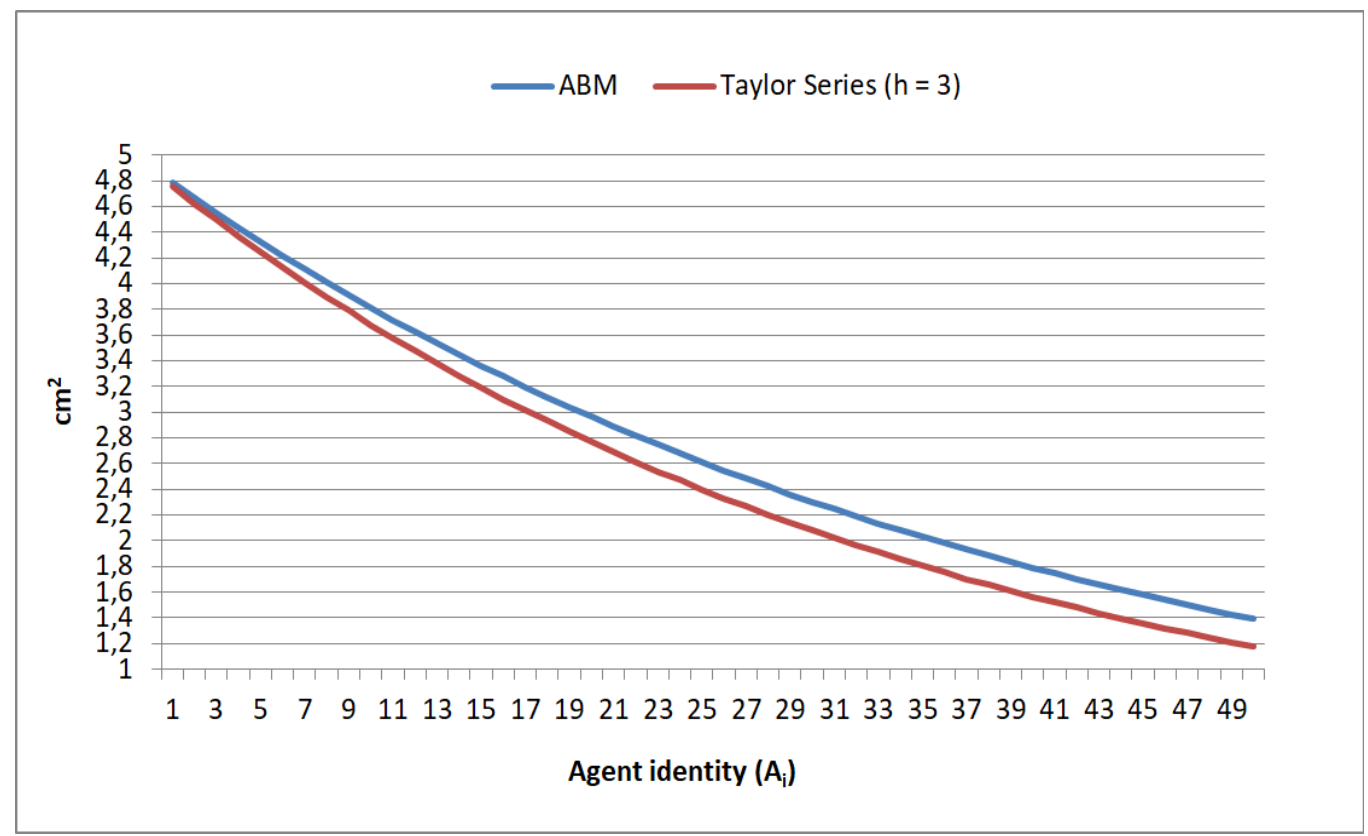

Figure 7. The function value of the agents for $h=3$ agent_count.

In Figure 7, the Taylor Series has predicted the function value of the agents at a distance of 3 step sizes from each other. When calculating the function value of the next agent by applying the Taylor series, the step size (h) is determined as 3 which is the agent count (equation (6)) between the current agent $\left(x_{i}=A_{i}\right)$ and the next agent $\left(\mathrm{X}_{\mathrm{i}+1}=\mathrm{A}_{\mathrm{i}+3}\right)$. 


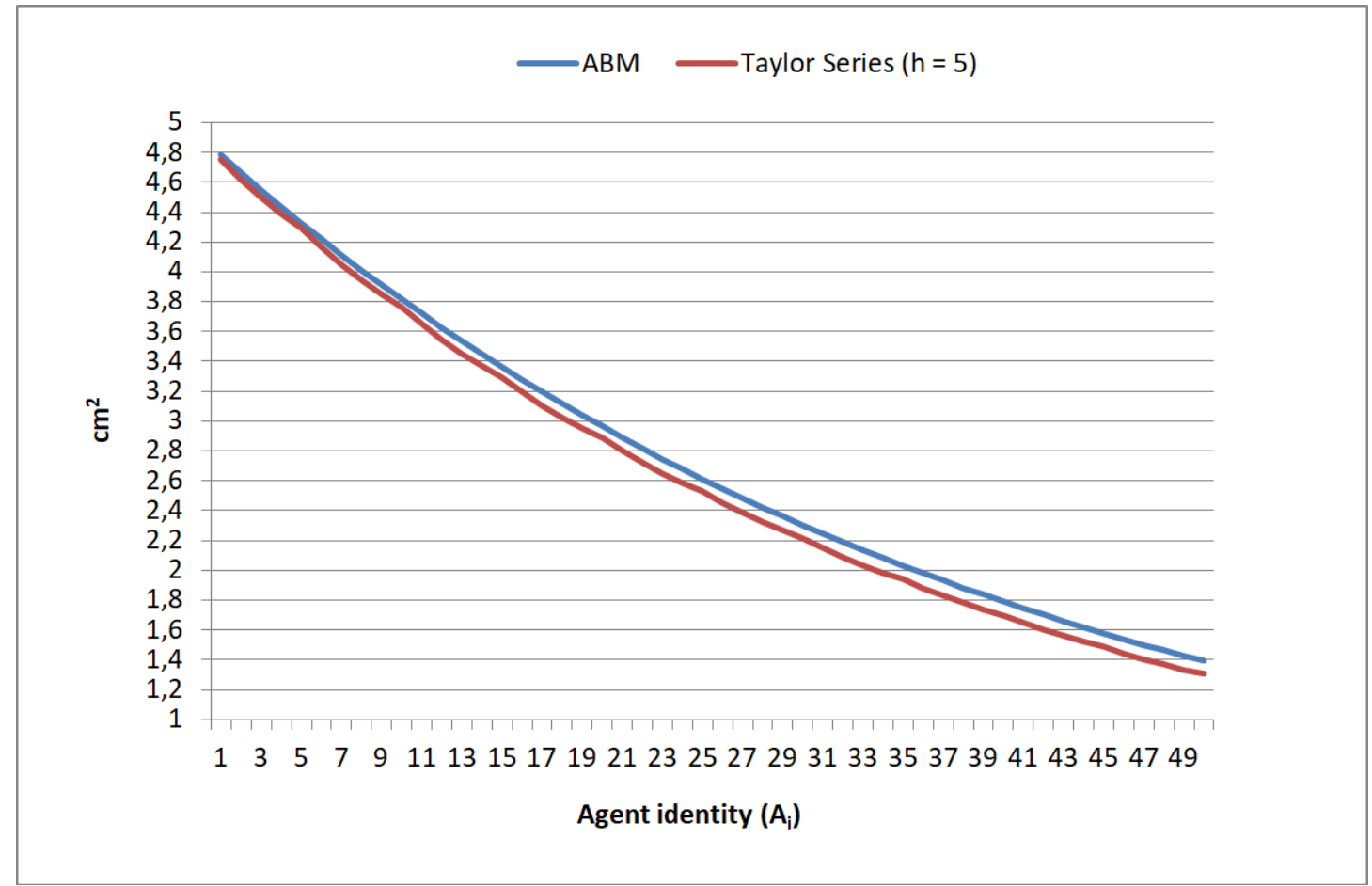

Figure 8. The function value of the agents for $h=5$ agent_count.

In Figure 8, the Taylor Series has predicted the function value of the agents at a distance of 5 step sizes from each other. When calculating the function value of the next agent by applying the Taylor series, the step size (h) is determined as 5 which is the agent count (equation (6)) between the current agent $\left(\mathrm{x}_{\mathrm{i}}=\mathrm{A}_{\mathrm{i}}\right)$ and the next agent $\left(\mathrm{X}_{\mathrm{i}+1}=\mathrm{A}_{\mathrm{i}+5}\right)$.

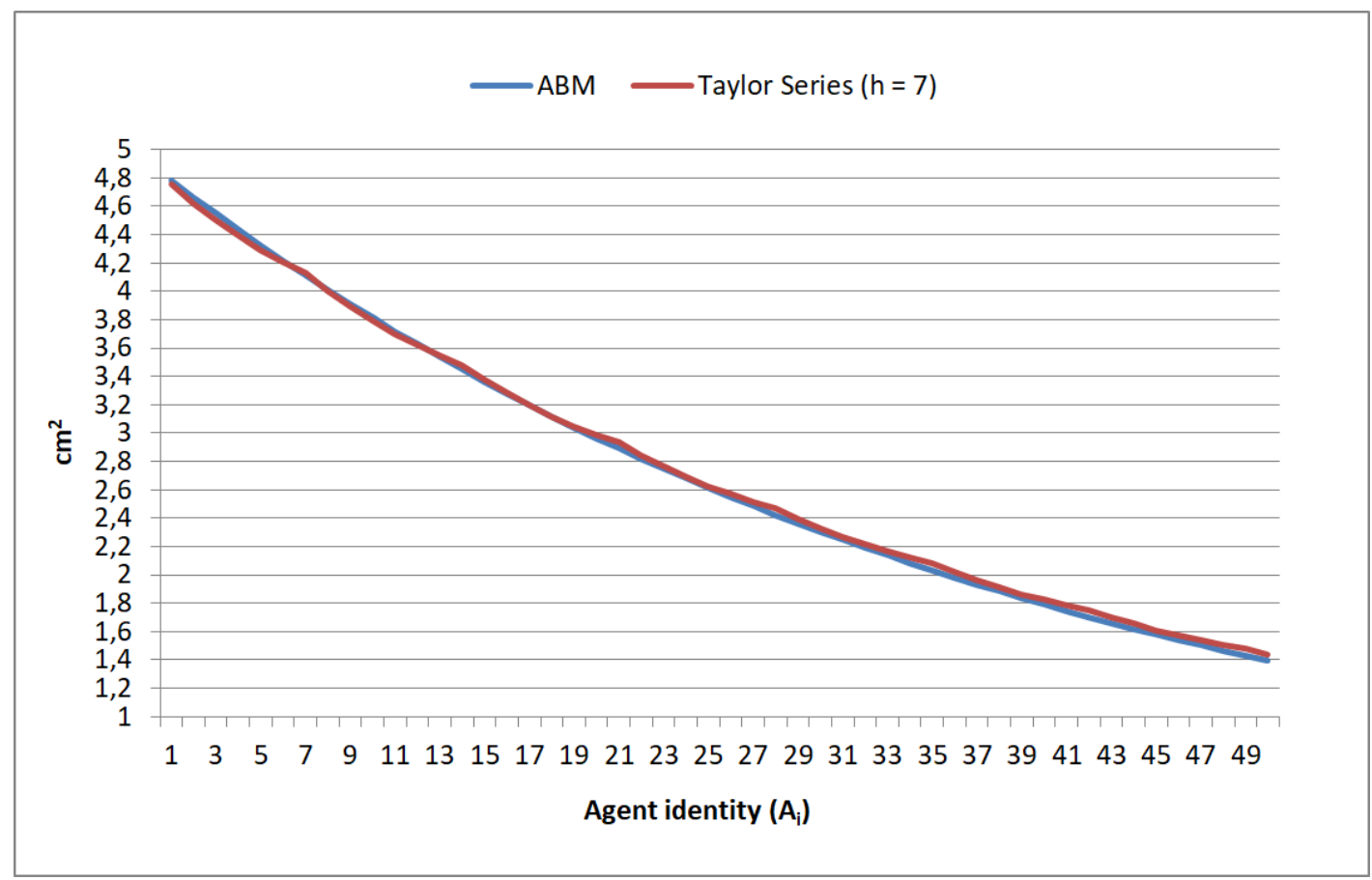

Figure 9. The function value of the agents for $\mathrm{h}=7$ agent_count.

In Figure 9, the Taylor Series has predicted the function value of the agents at a distance of 7 step sizes from each other. When calculating the function value of the next agent by applying the Taylor series, the step size (h) is determined as 7 which is the agent count (equation (6)) between the current agent $\left(\mathrm{x}_{\mathrm{i}}=\mathrm{A}_{\mathrm{i}}\right)$ and the next agent $\left(x_{i+1}=A_{i+7}\right)$. 
Figure 9 shows that the Taylor Series has provided a better estimate of the function value of the agents at a distance of 7 step sizes from each other than that of the function value of the agents at a distance of 5 step sizes from each other. When the step size (h) continues to increase shown as Figure 10, the Taylor series has exhibited the true relative error in the function values of the agents.

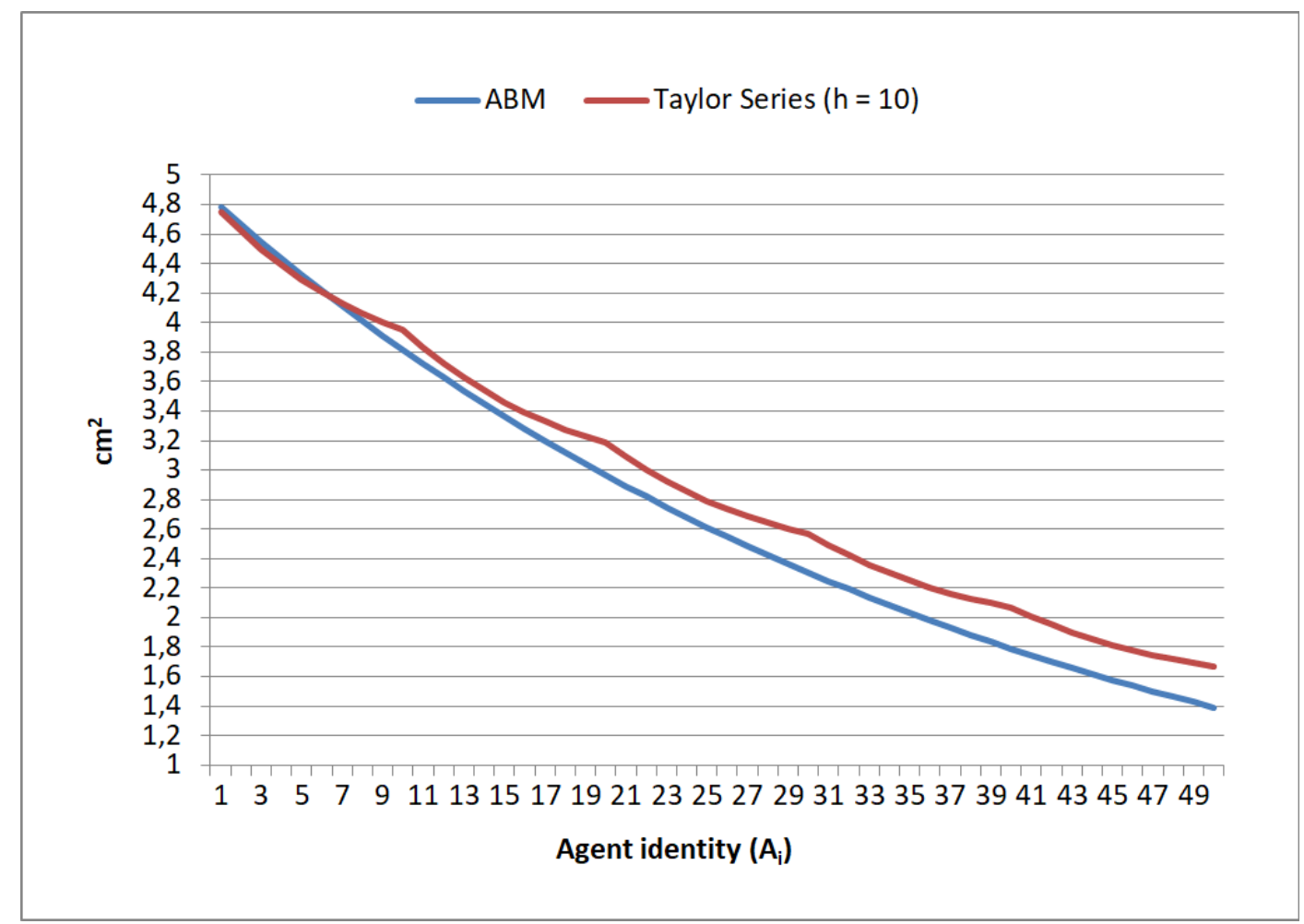

Figure 10. The function value of the agents for $h=10$ agent_count.

In this study, the function values of the agents determined by the ABM approach are considered as true values. As seen in the experimental analysis in this study, a true relative error occurs between the function values of the agents and the approximate values which are calculated with the Taylor Series expansion. The representation of the true percent relative error is formulated as (Chapra and Canale, 2015)

$$
\varepsilon_{t}=\frac{\text { true value-approximation }}{\text { true value }} 100 \%
$$

The true percent relative error is calculated for all agents based on step size (h). The mean of the true percent relative error for each experimental result is shown in the Table 1.

Table 1. The mean of the true percent relative error ( $\varepsilon$ t (\%))

\begin{tabular}{|c|c|}
\hline STEP SIZE (h) & $\boldsymbol{\varepsilon}_{\mathbf{t}} \mathbf{( \% )}$ \\
\hline 1 & 12,53 \\
\hline 2 & 10,37 \\
\hline 3 & 8,16 \\
\hline 4 & 5,96 \\
\hline 5 & 3,68 \\
\hline 7 & 1,24 \\
\hline 10 & 8,26 \\
\hline
\end{tabular}

The difference between the true values of the agents and their approximate values at distance $h$ is calculated by the true percent relative error for each agent. The step size (h) at which the true percent relative error is lowest indicates that we can estimate the function values of the agents that are at most $h$ distances. 


\section{Conclusions}

In this study, the function values of the agents that determine the behavior of a model are estimated by the Taylor Series. The rules of the agents' behaviors depend on the agents' attributes such as identity knowledge, radius, size, length, etc. In this study, we examine only one of the functions that determine the behavior of the agent in the model. This work offers a hybrid model perspective by applying the Taylor series to an agent-based model. This study has the potential to be developed to predict other behavioral functions of the agents. In future studies, the validation of the the agent-based cross-sectional model can be performed with the other local parameters of the agents by using Taylor Series. By applying different numerical methods to this study, the results can be tested, and the optimum solution can be observed within these methods.

\section{Conflict of Interest}

No conflict of interest was declared by the authors.

\section{References}

Bonabeau, E., 2002. Agent-based modeling: Methods and techniques for simulating human systems, Proceedings of the National Academy of Sciences, 99(3):7280-7287 pp.

Bora, Ş., Evren, V., Emek, S. and Çakırlar, I., 2017. Agent-based modeling and simulation of blood vessels in the cardiovascular system. Simulation: Transactions of the Society for Modeling and Simulation International, Special Section on Medical M\&S in Simulation. DOI: 10.1177/0037549717712602

Chapra S., C., Canale, R., P., 2015. Numerical Methods for Engineers, 7th Ed., Published by McGraw-Hill Education.

Di Marzo Serugendo, G., Gleizes, M.-P. and Karageorgos, A., 2005. Self-organization in multi-agent systems, The Knowledge Engineering Review, 20(2):165-189 pp. doi: 10.1017/S0269888905000494

Emek, S., 2018. Modeling and Simulation of Global Behaviors of the Self-Adaptive Systems by Using Agent Based System, PhD, Ege University, Izmir, Turkey.

Li, J. K-J., 2004. Dynamics of the vascular system. World Scientific Publishing, 1: 257p.

Macal, C. M. and North, M. J., 2009. Agent-Based Modeling and Simulation. In: WSC'09 Winter Simulation Conference, 86-98 pp.

Macal, C. M. and North, M. J., 2010. Tutorial on agent-based modeling and simulation. Journal of simulation, 4(3):151-162 pp.

Mangai, S., A., Sankar, B., R., Alagarsamy, K., 2014. Taylor Series Prediction of Time Series Data with Error Propagated by Artificial Neural Network, International Journal of Computer Applications, Vol. 89, No. 1. 